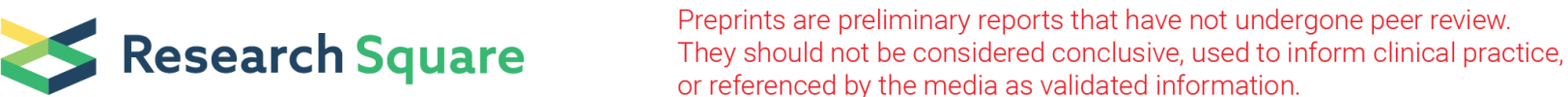

\section{Biodegradation of Polypropylene By Pseudomonas Aeruginosaisolated From Wastewater Associated Soil; A Potential Method To Eliminate The Plastic Pollution To Save Ecosystem}

Vijayalakshmi Selvakumar

Kangwon National University

Preethi Gopalsamy

Askoscen Probionics (R\&D)

Karnan Muthusamy

National Institute of Animal Science

Thenmozhi Manivel

Askoscen Probionics (R\&D)

Ramachandran Chelliah

Kangwon National University

Dinesh Kumar Sundarraj

Bharathidasan University

Sathammai Priya Narayanan

Affiliated to Bharathidasan University

Deog-Hwan Oh ( $\nabla$ deoghwa@kangwon.ac.kr)

Kangwon National University https://orcid.org/0000-0002-7472-0436

Research Article

Keywords: SARS-CoV-2,Polypropylene, Face masks,Biodegradation,Pesudomonas aeruginosa

Posted Date: October 25th, 2021

DOI: https://doi.org/10.21203/rs.3.rs-1002388/v1

License: (c) (1) This work is licensed under a Creative Commons Attribution 4.0 International License.

Read Full License 


\section{Abstract}

The face mask introduction in SARS-CoV-2 pandemic situation, one of the precautionary measure to reduce the rate of transmission of infection from person to person. There are many type of of face masks enter into our global market with various size and designs. Among those, surgical mask belongs to secure an important place and this aimed to evaluate the degrading efficiency disposable face masks (single use face masks). The present study dealt with, biodegradation of face masks which is made of polypropylene with the help of bacterial strainPesudomonasaeruginosaisolated from the plastic waste dumping sites in an around the Tiruchirappalli, India. The bacteriacould degrade PP mask via the formation of biofilm on a solid medium. To degrade the PP, the mask pieces were incubated with the culture of $P$. aeruginosain three different solid and liquid medium (nutrient agar, Bushnell Haas agar and mineral salt medium) for 30 days at $37 \llbracket$ C. The microbial degradation(up to $33 \%$ of weight reduction of PP films within 30 days) was proved by surface changes along with the variation in the intensity of functional groups as well as carbonyl index variations using Field-Emission Scanning Electron Microscopy (FE-SEM) and Fourier Transform Infra-Red Spectroscopy (FTIR) analysis. These results suggested that Paeruginosa strain can prove to be a suitable candidate for polypropylene mask biodegradation without causing any impairment to our health or environment.

\section{Introduction}

The ongoing quick universal spread of SARS-CoV-2 pandemic situation has led to the critical efforts to diminish transmission, leading to significant and extensive socioeconomic disruption(Sohrabiet al, 2020). On or after 3rd March 2020, the confirmed COVID-19 cases are about 90,870. From that confirmed cases 80,304 were confined to China. The remaining 10,566 cases were belongs to other 72 countries including Japan, United Nations and Australia of these cases 166 were fatal (the Japan, Philippines, Italy, France, Iran, Australia, Korea, Thailand and the United Nations). It is important to note that these data's were depicted laboratory - confirmed results only(WHO, 2020).Near July 2020, over 10 million cases have been reported globally, as well as around 50,000 death cases were recorded with going on spread in most of the parts of our earth(COVID, 2020). The corona virus (COVID-19) pandemic has caused the development of emergency responses and progressive moves were aimed to deal with and overcoming COVID-19 virus while reduces the exposures and supporting healthy life of all people around the world. One of such precautionary measure designed to minimize the community spread of COVID-19 transmitted via droplet is the compulsory wearing of plastic- based personal protective equipment (PPE) by the healthcare workers and face masks for the public leaving their homes for important necessary reasons(Benson et al, 2021).

The use of face masks by public people can minimizes the community spread of COVID-19, but it also develops severe troubles for our ecosystem. The number of face masks used in 49 countries of Asia was estimated from the COVID-19 pandemic database on July 31, 2020. The result of estimated value of the daily face mask use in Asia is 2.2 billion(Sangkham, 2020). There are three types of face masks can use in current situation i) Respirator Mask (N95, FFP2), ii) Surgical or Medical mask and iii) Non-certified 
disposable- mask (cloth mask)(Dharmarajet al, 2021). Top and bottom layers of disposable (single use) face masks were made up of woven fabric and the middle layer were meltdown polypropylene polymers. It was estimated that the authors models were generated 6.88 billion (approximately 206,470 $t$ ) around the world each day, which are eventually sent to land filling or incinerated after use(Nzediegwu and Chang, 2020). Also, the used face masks can be inappropriately spotted everywhere from the city streets to local parks, due to its lightweight, the rain water and wind can move this mask freely into city streets or rivers and oceans, where it was fragmented into microplastics(Prataet al, 2020; Saberianet al, 2021). In addition, the face masks used as single purpose are made up of non- biodegradable and take more than hundreds of years to break down in the environment(Saberianet al, 2021; Dhawanet al, 2019). As a result, a multidisciplinary approach is needed immediately to fight against the COVID-19 pandemic as well as to reduce the environmental troubles associated with the disposal of used personal protective equipment's.

In order to overcome the negative environmental issues due to the pandemic situation many authors works to reduce the pandemic-generated waste management in an innovative way. One of the best and eco-friendly approaches is the use of microorganisms for waste management. The investigation of microorganisms towards polypropylene and polyethylene degradation is well studied by several authors. Biodegradation is one of the best ability of microorganisms to persuade abiotic degradation by physical, chemical of enzymatic action(Albertssonet al, 1987). For biodegradation process microorganisms were well suited for their ability to possess enzymes and the small size make them able to contact with the surface of the plastic(Devi et al, 2016). The microbial exo-enzymes can breaks the complex polymers to simpler one which was then easily pass through the semi-permeable outer membranes and then it can be used as carbon and energy sources of the microbes $(\mathrm{Gu}, 2003)$. A number of bacterial and fungal genera were reported by several researchers for microplastic degradation process including Pseudomonas sp(Gupta and Devi, 2020; Vague et al, 2019; Muniret al, 2018; Roberts et al, 2020). The ability of microbes to mediate plastic degradation directly there are several gut bacterial species were isolated from worms and verified. In vitro depolymerization of PE can be done by the bacterial strains namely Enterobacterasburiae YT1 and Bacillus sp. YP1 isolated from the waxworms(Yang et al, 2014). P.aeruginosa isolated from the guts of superworms can have extradinarybiodegradative ability on four types of plastics (PE, PP, PPS and PP). On the other hand the efficiency of biodegradation varied from one plastic to another, the fastest biodegradation occurs on PE(Lee et al, 2020). The present study was aimed to evaluate the biodegradation ability of Paeruginosa on surgical face mask with eco-friendly manner and to save our environment from pandemic- generated wastes.

\section{Materials Methods}

\section{Chemicals and Reagents}

The soil sample was collected from the plastic waste dumping sites around the Tiruchirappalli district, Tamil Nadu, India. Then the sample was carefully transported for our laboratory in order to isolate the plastic degrading Pseudomonas sp. The used face masks were not allowed to use in our laboratory test due to the laboratory rules and regulations during this covid-19 pandemic situation. Therefore, clean 
surgical face masks were used in the experiments (ear loops were removed from the masks). The chemicals used in our study were purchased from Hi-media laboratory, India.

\section{Isolation of bacteria from soil sample}

Serially diluted soil sample was inoculated onto the previously prepared sterile nutrient agar medium (NAM) and incubated at 37囚 C for 24-48 hours in order to isolating bacteria from the sample. Individual colonies obtained after incubation were used for the preparation of pure culture. The pure colonies were subjected to Gram's staining for primary identification. Then the isolated bacterium was maintained on Nutrient agar at $4 \llbracket \mathrm{C}$ in our laboratory for performing the biodegradation experiment in our present study.

\section{Biochemical identification of the bacterium}

The isolated bacterial strain was identified based on the basic biochemical tests. The biochemical tests were conducted on 24 hours old cultures grown on Nutrient agar medium at $37 \rrbracket \mathrm{C}$. Indole test was performed in order to determine their tryptophan utilization ability according to the supplier protocol. Catalase analysis was conducted according to Kumariet al, 2013. Citrate metabolism was studied by inoculating bacterial colonies on Simmon's Citrate agar (According to supplier protocol).Oxidase test was conducted in order to check the bacteria that possess the enzyme cytochrome oxidase. Sugar fermentation test (Glucose, Lactose, and Sucrose) was studied by inoculating bacteria onto the TSI agar medium (According to supplier protocol). Motility and H2S production test were conducted using SIM medium (According to supplier protocol). The MR-VP test was done to identify the isolate as facultative anaerobe by their sugar fermentation profiles. Also the bacterium was streaked onto the Cetrimide agar for further clarification of the bacterial identification processes.

\section{Investigation of Biodegradation of Polypropylene Mask Pretreatment of Polypropylene mask pieces}

The metal strips and ear loops were removed from the masks. Then the masks were pretreated by the method previously described by Gupta and Devi (2020). For this process the masks were cut into $(3 \times 3$ $\mathrm{cm}$ ) pieces and soaked into the solution containing $7 \mathrm{ml}$ of Tween- $80,10 \mathrm{ml}$ of bleach and $983 \mathrm{ml}$ of sterile water for 30-60 minutes with continuous stirring. Then the mask pieces were washed with distilled water at room temperature. Then the pieces were surface sterilized with $70 \%$ ethanol for 30 minutes and allowed to dry at $45 \rrbracket \mathrm{C}$. After drying the mask pieces were weighed using the weighing balance and initial weight of the pieces was noted.

\section{Biodegradation Experiment}

The bacterium P.aeruginosa was aseptically inoculated by carpet culture method on to Nutrient agar, $\mathrm{BHM}$ agar and MSM agar plates. After inoculation the pretreated polypropylene mask pieces $(0.1 \mathrm{~g})$ were aseptically placed over the inoculated plates using sterile forceps and incubated at 30खC and 37凶C separately for one month (30 days). The agar plates containing the same quantity of mask pieces without bacterial inoculation were maintained at the same temperature as negative control. Also the 
pretreated mask pieces were incubated with P.aeruginosa in NB, BHM broth and MSM broth (each media contain $0.1 \mathrm{~g}$ of mask pieces) and the liquid media containing same quantity of mask pieces without culture maintained at the same duration as control.

\section{Experimental set up}

T1A- $0.1 \mathrm{~g}$ of pretreated mask pieces+ P.aeruginosa (in NA plates)

T1B- $0.1 \mathrm{~g}$ of pretreated mask pieces+ P.aeruginosa (in Nutrient Broth)

C1A- $0.1 \mathrm{~g}$ of pretreated mask pieces in NA plates (without inoculums)

C1B- $0.1 \mathrm{~g}$ of pretreated mask pieces in nutrient broth (without inoculums

T2A- $0.1 \mathrm{~g}$ of pretreated mask pieces+ P.aeruginosa in Bushnell Haas agar plates (BHM agar)

T2B- $0.1 \mathrm{~g}$ of pretreated mask pieces+ P.aeruginosa (in BHM Broth)

C2A- $0.1 \mathrm{~g}$ of pretreated mask pieces in BHM agar plates (without inoculums)

C2B- $0.1 \mathrm{~g}$ of pretreated mask pieces in BHM broth (without inoculums)

T3A- $0.1 \mathrm{~g}$ of pretreated mask pieces+ P.aeruginosa in Mineral Salt agar plates(MSM agar)

T3B- $0.1 \mathrm{~g}$ of pretreated mask pieces+ P.aeruginosa (in MSM Broth)

C3A- $0.1 \mathrm{~g}$ of pretreated mask pieces in MSM agar plates (without inoculums)

C3B- $0.1 \mathrm{~g}$ of pretreated mask pieces in MSM broth (without inoculums)

\section{Monitoring the planktonic growth of P.aeruginosa strain}

The growth of the Paeruginosa in the liquid media such as NB, BHM and MSM owing to the presence of PP film and the characteristics of the biofilm produced on the surface of the polymer throughout the period of 30 days ( 1 month) with 15 days interval was scrutinized as explained below. Before analyzing the biofilm, polymer samples were taken away from the media by means of sterile forceps and cautiously rinsed with sterilized distilled water in order to confiscate the slackly adhered bacteria. Then the biofilm was removed from the surface of the polymer by subjecting the sample to a mild water bath sonication in $1 \mathrm{ml}$ of $0.85 \%$ saline solution, for a total of $4 \mathrm{~min}$ at $1 \mathrm{~min}$ intervals. Thus obtained saline solution was serially diluted up to $10^{-7}$ and the aliquots were spreaded on Nutrient agar and the number colonies were calculated as CFU/ml (Arkatkaret al, 2010).

\section{Viability testing of Surface attached bacteria}

The viability of bacterial strains attached on the surface of the PP films was tested as per the method described by Andes et al(2004). PP films were removed from the media at 10 days interval and washed with sterile distilled water then it was subjected to mild bath sonication with $0.85 \%$ saline solution. The 
obtained solution was serially diluted and plated on NA and incubated at $35^{\circ} \mathrm{C}$ for $48 \mathrm{~h}$. Number of viable bacteria species were obtained as CFU/ml.

\section{Assessment of cell surface hydrophobicity of P.aeruginosa}

The hydrophobicity of the bacterial cell surface was determined using the BATH test by little modifications (Harshvardhan and Jha, 2013) was explained as follows: the bacteria were cultured in Nb medium until the growth of bacteria reach the mid-log stage. Then it was centrifuged and washed twice with phosphate urea buffer (PUM containing 17g K2HPO4, 7.26g KH2PO4, 1.8g Urea and 0.2g MgS04.7H2O per liter). After washing the cells were resuspended in PUM buffer to an OD at 400nm (OD400) value of 1.0-1.2. Aliquots of $1.2 \mathrm{ml}$ of above obtained suspension were added to a series of test tubes containing increased volumes of xylene (ranges from 0-0.2ml) and shake well for 10 min then allowed to stand for $2 \mathrm{~min}$ in order to facilitate phase separation. The OD400nm of the lower aqueous phase was then measured and noted as OD1. The cell surface hydrophobicity was stated as the percentage of the xylene -bound cells described as the fraction of the cells expelled from the aqueous phase. Plain PUM buffer served as the blank. Therefore, the percentage of adhering cells are represented using the following formula: Cell Surface Hydrophobicity $(\%)=\left(\left(O D_{0}-O D_{10}\right) / O D_{0}\right) \times 100\left(O D_{0}\right.$ is the initial OD of the aqueous phase).

\section{Determination of Dry weight of the recovered Mask pieces}

The residual mask pieces were recovered from the culture plates after the completion of one month incubation. The bacterial biomass adhering on the polypropylene mask surface was washed with the sodium dodecyl sulfate (SDS) solution ( $2 \% \mathrm{v} / \mathrm{v})$ for 2 hours. After the pieces were rinsed with distilled water in order to remove any impurities on the surface and dried overnight at 45囚C. Then the degraded mask pieces were weighed using weighing balance and the percentage of bio degradation (weight loss) was calculated using the following formula

$$
\text { Biodegradation }(\%)=\frac{\text { Initialweight }- \text { Finalweight }}{\text { Initialweight }} \times 100
$$

\section{Surfaceanalysis of mask pieces}

\section{Scanning electron microscopy}

The mask pieces treated with the bacterium P.aeruginosa for 30 days were removed from the medium and subjected to FE-SEM for the observing biofilm formation and surface erosion. Bacterial morphology of biofilm on PP mask surface was observed. Before the observation, the treated mask pieces were washed with $0.01 \mathrm{M}$ phosphate buffer solution for $2 \mathrm{~min}$ in order to remove the excess medium adheres with the bacterial colonies. For observing the surface alteration of treated mask pieces, the pieces were washed with $2 \%$ SDS along with warm water for 10-20 min to facilitate the complete removal of bacterial biomass. After the process was completed, the mask pieces were fixed in $4 \%$ glutaraldehyde at $4^{\square} \mathrm{C}$ for 2 hours and dehydrated with $50 \%$ ethanol for $30 \mathrm{~min}$. Then the recovered mask pieces were incubated 
overnight in $70 \%$ ethanol at room temperature. Then the pieces were dried, mounted and sputter coated with gold for 40 s and scanned through FE-SEM.

\section{Fourier Transform Infra- Red Spectroscopy (FTIR analysis)}

The structural and functional group alteration in the polypropylene mask pieces were analyzed by FTIR spectra in the frequency range of $4000-400 \mathrm{~cm}^{-1}$ were used at a $1 \mathrm{~cm}^{-1}$ resolution. The relative absorbance intensities of the keto carbonyl bond, ester carbonyl bond, terminal double bond (vinyl) and the internal double bond with methyl bond were evaluated using the following formula: Keto carbonyl bond Index $(\mathrm{KCBI})=$ I1715/I1465; Ester Carbonyl bond index(ECBI) = I1740/I1465; Vinyl Bond Index $(\mathrm{VBI})=\mid 1650 / / 1465$ and the Internal Double Bond Index $($ IDBI $)=1908 /$ I1465. The degree of biodegradation was measured usindthe Carbonyl index because its value depends on the degradation. The percentage of crystallinity of the polypropylene mask film was measured according to the method described by Zerbiet al (1989)(Zebriet al, 1989).

\section{Results And Discussion}

Isolation and Identification of Pseudomonas sp.

Typical colonies of bacterial isolates were sub-cultured on nutrient agar and incubated at $37^{\circ} \mathrm{C}$ for $24 \mathrm{~h}$. Isolated identification was performed according to the morphological, staining reaction, cultural and various biochemical characteristics by following the Bergey'sMannual of Systematic Bacteriology. Based on presumptive identification of bacteria by Gram's staining protocol Pseudomonas sp. was identified as gram negative rod. Depending upon the different biochemical characterization the isolated bacteria was identified as $P$. aeruginosa strain (Fig. 1). It was further confirmed by streaking the strain onto the Cetrimide agar which is selective media for isolating P.aeruginosa. The isolates were showed green pigmented, circular and opaque colony morphology after incubation. Similar to ours study, the another author reported that the isolated bacteria were also grown in milk agar with cetrimide for the preliminary detection of Pseudomonas spp.(Szitaetal, 1998). Based on the results it was reasonable, to identify the isolated bacterium as $P$. aeruginosa. This identified strain was used for the biodegradation of pre-treated polypropylene mask pieces. The bacterium P.aeruginosa isolated from Sisdol land fill site and Sanothimi household garbge site soil in Nepal has similar biochemical properties(Badahitet al, 2018). It has been reported that $P$. aeruginosa ISJ14 showed tremendous efficiency to degrade low density polyethylene (LDPE) in BHM(Gupta and Devi, 2020).In contrast, the present study reports for the first time that P.aeruginosastrain is capable of biodegradation of surgical face mask made up of hardy PP like substance.

\section{Cell surface hydrophobicity of bacteria}

The capability of bacteria to use any substrate depends upon its development on and adherence to that substrate. The adhesion ability of bacteria to either hydrophilic or hydrophobic surfaces is addressed by a number of physical factors, together with the forces which help the bacterium to adhere to solid 
substrates, properties of that substrate and the nature of bacteria. For the most part, a hydrophobic bacterium favors a hydrophobic surface for adhesion, though the inverse is substantial for bacterium with hydrophilic properties(Gupta and Devi, 2020). In the current investigation, the hydrophobicity of midlog phase cells of P.aeruginosa at $0.2 \mathrm{ml}$ concentration of xylene, we showed a significance increase in hydrophobicity (30.39\%) (Table 1 and Fig. 2). These results are in agreement with Gupta and Devi (2020), who observed that bacterial cells in log phase are more hydrophobic in nature. Previous study also documented similar findings, where, maximum increase in hydrophobicity i.e, the isolates Kocuriapalustris $\mathrm{M} 16$ and Bacillus subtilis $\mathrm{H} 1584$ showed approximately $24 \%$ turbidity reduction at $0.25 \mu \mathrm{l}$ and a maximum reduction of turbidity $32 \%$ at $150 \mu$ concentration of hydrocarbon like hexadecane(Harshvardhan and Jha, 2013). Another recent research also reported that the hydrophobobicity of L.monocytogenes strain CICC 21332 showed lowest hydrophobicity (12.5\%) and the strain FSIS 57034 displayed highest percentage of $\mathrm{CSH}(74.81 \%)$ at $1 \mathrm{ml}$ of xylene concentration(Fun et al, 2020).

Table-1. Cell surface Hydrophobicity of P.aeruginosa

\begin{tabular}{|llll|}
\hline S. No & Conc. Of Xylene & OD value & \%Hydrophobicity \\
\hline 01 & 0 & 1.02 & 0 \\
\hline 02 & 0.05 & 0.89 & 12.74 \\
\hline 03 & 0.10 & 0.82 & 19.61 \\
\hline 04 & 0.15 & 0.76 & 25.49 \\
\hline 05 & 0.20 & 0.71 & 30.39 \\
\hline
\end{tabular}

\section{Growth of P.aeruginosa planktonic cells and surface attached cells on PP films}

The growth pattern of bacteria attached on the surface of PP film was examined in planktonic cells and viable count of surface attached bacterial species (Arkatkaret al, 2010; Andes et al, 2004). The data illustrated in Figures 3 and 4 show a surface attachment pattern of bacteria on the PP film. The bacterial cell growth was characterized by a precipitous raise in planktonic cells after 15 and 30 days of incubation and is also revealed by a raise in the surface-attached bacterial mass. After 15-20 days of incubation the growth of P.aeruginosa was able to reach a steady, almost $10^{7} \mathrm{CFU} / \mathrm{ml}$ in all the liquid media used. In all the three media, biofilm formation patterns exhibited analogous to that of the growth of planktonic cells. The results recommend that P.aeruginosa cells exhibit better colonization, formation of biofilm and fractional biodegradation of PP film in all the three media. These observations not only specify high affinity of P.aeruginosa cells for the PP film but also increase the possibilities of P.aeruginosa cultures to form biofilms by hydrophobic interactions at low levels of carbon availability. In considering of concurrence model, the course of action of biofilm formation by microbes is began when the planktonic growth of cells achieves high density and help for the attachment of bacterial cells to a surface through 
cell signaling, likewise bringing about the development of microcolonies that will eventually frame the mature biofilms (Costertonet al, 1999). This biofilm population is diverse and comparativelysteadyintendedforextensiveperiod of time (Bodtkeret al, 2008). Conversely, this circumstance is not inevitably familiar to the entire biofilm forming bacterial species. In our investigation, PP films provided as a substrate for the attachment and biofilms formation as well as a source of carbon for P.aeruginosa strain. The extended incubation of P.aeruginosa with PP films resulted in a solid biofilm on PP surface which may lead to the fractional deduction of this polymer. Likewise, the formation and maintenance of active biofilm throughout the 30 days of incubation possibly will perhaps by the utilization of low molecular massmaterials in the polymer. Similar findings were recorded in earlier studies such as biodegradation of untreated films of polyethylene by P.putita IRN22, Micrococcus /uteus IRN20, Acinetobacterpittii IRN19 (Montaveret al, 2019) and other bacterial genera including Delftia, Stenotrophomonas and Comamonas(Peixotoet al, 2017) and Galleria melonella isolated from the gut of the wax worm also have been establish the capabilities of PE degradation (Cassoneet al, 2020).

Table-2. Viability of P.aeruginosa on different day interval

\begin{tabular}{|lllll|}
\hline S.No & Days & $\begin{array}{l}\text { Cfu/ml in } \\
\text { NB(10 }\end{array}$ & $\begin{array}{l}\text { Cfu/ml in BHM } \\
\left(10^{-7} \text { dilution }\right)\end{array}$ & $\begin{array}{l}\text { Cfu/ml in MSM } \\
\left(10^{-7} \text { dilution }\right)\end{array}$ \\
\hline 1 & 0 & $1.07 \times 10^{5}$ & $0.8 \times 10^{5}$ & $0.92 \times 10^{5}$ \\
\hline 2 & 10 & $2.01 \times 10^{6}$ & $1.9 \times 10^{6}$ & $1.92 \times 10^{6}$ \\
\hline 3 & 20 & $2.02 \times 10^{7}$ & $1.95 \times 10^{7}$ & $1.99 \times 10^{7}$ \\
\hline 4 & 30 & $1.97 \times 10^{7}$ & $1.98 \times 10^{7}$ & $1.98 \times 10^{7}$ \\
\hline
\end{tabular}

Table-3.Monitoring the planktonic growth of P.aeruginosa (log cfu/ml)

\begin{tabular}{|llll|}
\hline Media & 0 DAY & 15TH DAY & 30TH DAY \\
\hline NB & $0.9 \times 10^{5}$ & $2.0 \times 10^{5}$ & $2.08 \times 10^{5}$ \\
\hline BHM & $1.1 \times 10^{7}$ & $1.9 \times 10^{7}$ & $2.07 \times 10^{7}$ \\
\hline MSM & $1.2 \times 10^{7}$ & $2.0 \times 10^{7}$ & $2.12 \times 10^{7}$ \\
\hline
\end{tabular}

\section{Dry Weight Determination of recovered Polypropylene Mask pieces}

The residual polypropylene mask strips were recovered from the media after one month (30 days) of incubation. The adhered media and bacterial biomass were washed with appropriate solutions and allowed to air dry. The air dried films were weighed and the final weight loss for P.aeruginosa in respective 
culture media (NA, NB, BHM agar, BHM broth, MSM agar and MSM broth) has been provided in table 4 and Fig. $5 \mathrm{a}$ and $5 \mathrm{~b}$. The growth kinetics of the Paeruginosastrain in media demonstrated its colonization on PP mask pieces surface consequently, reduction in weight was observed as a result of utilization of pp mask film as nutrient source. Our study describes the potency of the P.aeruginosastrain was very high because it shows 26 and $33 \%$ of weight reduction in case of PP films placed in NB and NA, 28 and 31\% weight reduction observed in BHM agar and BHM broth and 24 and $23 \%$ weight reduction was noted in MSM agar and MSM broth after one month duration (30 days). Similar findings were reported by several other researchers on LDPE surface (Kapriet al, 2010; Shah et al, 2015; Sahet al, 2010). Whereas, the LDPE film treated by P.aeruginosastrain showed $20 \%$ reduction after 120 days of treatment also has been reported (Kyawet al, 2012). Several other researchers also reported the same findings on LDPE surface (Kapriet al, 2010; Shah et al, 2015; Sahet al, 2010). Whereas, the LDPE film treated by P.aeruginosastrain showed $20 \%$ reduction after 120 days of treatment also has been reported (Kyawet al, 2012). However, the recent study provide strong evidence for PP microplastic degradation by Rhodococcus sp. strain 36 with $6.4 \%$ degradation and Bacillus sp. strain 27 with $4 \%$ also depicted the good degradation capacity of bacterial strains (Autaet al, 2018).

Table-4. Weight reduction of PP mask pieces after 30 days treatment with P.aeruginosa on different media sources

\begin{tabular}{|lllllll|}
\hline Media sources & \multicolumn{2}{c}{ Initial weight (g) } & \multicolumn{2}{c|}{ Final weight(g) } & \multicolumn{2}{c|}{ \% Weight reduction } \\
\cline { 2 - 7 } & Control & Treated & Control & Treated & Control & Treated \\
\hline Nutrient agar & 0.1 & 0.1 & 0.1 & 0.074 & 0.0 & 26 \\
\hline Nutrient broth & 0.1 & 0.1 & 0.1 & 0.067 & 0.0 & 33 \\
\hline BHM agar & 0.1 & 0.1 & 0.1 & 0.072 & 0.0 & 28 \\
\hline BHM broth & 0.1 & 0.1 & 0.1 & 0.069 & 0.0 & 31 \\
\hline MSM agar & 0.1 & 0.1 & 0.1 & 0.076 & 0.0 & 24 \\
\hline MSM broth & 0.1 & 0.1 & 0.1 & 0.077 & 0.0 & 23 \\
\hline
\end{tabular}

\section{Surface Changes Analysis}

The surface morphology changes on the PP mask pieces before and after biotic exposure was investigated with the help of Field- Emission Scanning Electron Microscope (FE-SEM). The Fig. 6a, 6b and 6cshowed that the surface changes recorded during FE-SEM analysis both the PP mask films treated with P.aeruginosastrain(T1A, T1B, T2A, T2B, T3A and T3B)and untreated negative control(C1A, C1B, C2A, C2B, $\mathrm{C} 3 \mathrm{~A}$ and $\mathrm{C} 3 \mathrm{~B}$ ) after 30 days of treatment. It was examined that signs of surface deterioration appeared on the PP mask films treated withP.aeruginosastrain after 30 days of incubation. On the other hand, the control film (un-treated with P.aeruginosastrain) keep hold of a smooth surface under same incubation condition was noted. Similar findings were reported in surface morphology of the LDPE films treated with 
Pseudomonas spp. by SEM after 40, 80 and 120 days of incubation (Kyawet al, 2012). The another study also reported that the P.aeruginosa ISJ14 used to treat LDPE film showed maximum deterioration after 60 days of treatment when observed under the FE-SEM (Gupta and Devi, 2020). A cross reference to the earlier research studies on LDPE biodegradation, many authors have reported the similar morphological changes on LDPE degradation by Aspergillusspp. (Zahra et al, 2010). A.clavatus JASK1 (Gajendiranetal, 2016).

Structural Analysis using FTIR

Structural changes in biologically treated PP mask films were further analyzed with the help of FTIR.This investigation of the degraded PP films had shown the stretching of numerous functional groups after incubation with the P.aeruginosa strain. This was established by the alterations in the peaks of the FTIR spectra amidst the control and test samples in all the media used. Table $5 a, 5 b$ and $5 c$ recapitulate the sort of functional group implicated in stretching by the role of P.aeruginosa, the wave number and IR band position on the PP films.A considerable reduction in the Carbonyl Index was observed on the samples incubated with P.aeruginosastrain for 30 days. The drop in $\mathrm{Cl}$ with respect to the negative control was showed in Fig. 7a-7l. In our study, we observed maximum reduction in $\mathrm{Cl}$ on PP mask filmsincubated with P.aeruginosastrain for 30 days. Spectrophotometric variations of PP mask films and the value of $\mathrm{Cl}$ which determines the maximumdegradation when compared to un-treated negative control. Thus, our results suggested that theP.aeruginosastrain has great ability to degrade the PP mask films. The LDPE film incubated with P.aeruginosa PAO1 showed maximum reduction in $\mathrm{Cl}$ was reported by (Kyawet al, 2012; Skariyachanetal, 2015). In the present study, FTIR analysis affords a close view of N-H stretching of aldehydes group at $3190.18 \mathrm{~cm}^{-1}$. The $\mathrm{C}-\mathrm{C}$ absorption peaks were shifted as evident at $1255.18,1302.34$, 1794.87, 2427.49 and $2617.26 \mathrm{~cm}^{-1}$. A similar observation was reported by several authors (Howard and Hilliard, 1999). Our results were supported by various previous research studies noticed the formation of functional groups and disappearance of these groups in the LDPE degradation using the strain Bacillus amyloliquefaciens(Das etal, 2015). In relation to our study, (Gajendiranet al, 2016) have also noticed visible modifications in the synthetic polymers undergo biodegradation, before and after exposure to microbes by FTIR analysis. The conformational changes on PP mask film were supported by the changes in the peak values of almost all functional groups (Fig .7a-7l).

Table-5a. Comparison of IR band position in the PP films after incubation with P.aeruginosa in NB and NA(both control and test) 


\begin{tabular}{|c|c|c|c|c|}
\hline S.No & $\begin{array}{l}\text { Incubation } \\
\text { period }\end{array}$ & $\begin{array}{l}\text { IR band position in } \mathrm{BHM} \\
\text { broth control-test }\left(\mathrm{cm}^{-1}\right)\end{array}$ & $\begin{array}{l}\text { IR band position in BHM } \\
\text { Agar control-test }\left(\mathrm{cm}^{-1}\right)\end{array}$ & $\begin{array}{l}\text { Functional } \\
\text { group involved }\end{array}$ \\
\hline 1 & \multirow[t]{4}{*}{30 days } & $572.18-460.23$ & $1002.24-808.93$ & C-X stretching \\
\hline 2 & & $2950.10-2838.92$ & $2918.97-2917.61$ & $\mathrm{C}-\mathrm{H}$ stretching \\
\hline 3 & & $2916.61-2722.13$ & $2947.73-2838.92$ & $\mathrm{C}-\mathrm{H}$ stretching \\
\hline 4 & & $3762.08-3189.68$ & $3761.52-3189.68$ & $\mathrm{O}-\mathrm{H}$ stretching \\
\hline
\end{tabular}

Table-5b. Comparison of IR band position in the PPfilms after incubation with P.aeruginosa in BHM broth and BHM agar (both control and test)

\begin{tabular}{|c|c|c|c|c|}
\hline S.No & $\begin{array}{l}\text { Incubation } \\
\text { period }\end{array}$ & $\begin{array}{l}\text { IR band position in BHM } \\
\text { broth control-test }\left(\mathrm{cm}^{-1}\right)\end{array}$ & $\begin{array}{l}\text { IR band position in BHM } \\
\text { Agar control-test }\left(\mathrm{cm}^{-1}\right)\end{array}$ & $\begin{array}{l}\text { Functional } \\
\text { group involved }\end{array}$ \\
\hline 1 & \multirow[t]{4}{*}{30 days } & $572.18-460.23$ & $1002.24-808.93$ & C-X stretching \\
\hline 2 & & $2950.10-2838.92$ & $2918.97-2917.61$ & $\mathrm{C}-\mathrm{H}$ stretching \\
\hline 3 & & $2916.61-2722.13$ & $2947.73-2838.92$ & $\mathrm{C}-\mathrm{H}$ stretching \\
\hline 4 & & $3762.08-3189.68$ & $3761.52-3189.68$ & $\mathrm{O}-\mathrm{H}$ stretching \\
\hline
\end{tabular}

Table-5c. Comparison of IR band position in the PPfilms after incubation with P.aeruginosa in MSM broth and MSM agar (both control and test)

\begin{tabular}{|llllll|}
\hline S.No & $\begin{array}{l}\text { Incubation } \\
\text { period }\end{array}$ & $\begin{array}{l}\text { IR band position in MSM } \\
\text { broth control-test }\left(\mathbf{c m}^{-1}\right)\end{array}$ & $\begin{array}{l}\text { IR band position in MSM } \\
\text { Agar control-test }\left(\mathbf{c m}^{-1}\right)\end{array}$ & $\begin{array}{l}\text { Functional } \\
\text { group involved }\end{array}$ \\
\hline 1 & \multirow{2}{*}{30 days } & $562.12-458.98$ & $460.00-459.35$ & C-X stretching \\
\cline { 1 - 4 } 2 & & $2839.02-2722.15$ & $2839.57-2838.65$ & C-H stretching \\
\hline 3 & & $2916.76-2838.83$ & $2918.00-2917.14$ & C-H stretching \\
\hline 4 & & $3760.91-3346.85$ & $3351.15-3190.32$ & O-H stretching \\
\hline
\end{tabular}

\section{Conclusion}

In sum, this work offered a versatile biological process to evaluate the degradation of disposable face mask used in this SARS-CoV-2 pandemic situation. The in vitro biodegradation of Paeruginosastrainin three different solid and liquid medium reflects the eco friendly approach. We observed a tremendous biodegradation efficiency of our isolates towards the PP based disposable face mask whose molecular weight was as high as 228,000 . The isolate has a capability to forming biofilm on PP surface and utilized it as a sole nutrient source for growth was reflected by weight reduction of PP mask films in comparison with un-treated control films (up to $33 \%$ of weight reduction within 30 days). Based on the results of FE- 
SEM as well as FTIR analysis, the P.aeruginosastrain is a best suited candidate for PP degradation without an UV treatment. However, further studies on enzyme based metabolic passages of P.aeruginosastrain are also recommended to better understanding of its tremendous role in the process of biodegradation.

\section{Declarations}

\section{Acknowledgements}

Authors are thankful to Askoscen Probionics (R\&D), Thiruchirappalli, Tamilnadu, India for the support.

Author contribution: Vijayalakshmi Selvakumar: Conceptualization, Methodology, Data curation, Writing - original draft, Writing - review \& editing ; Preethi Gopalsamy- Methodology, Data curation, Writing original draft, Writing - review \& editing; Karnan Muthusamy- formal analysis; Thenmozhi Manivel- writing and formal analysis; Ramachandran Chelliah- writing-review and editing; Dinesh Kumar Sundarraj- Software, Data curation, Writing - review \& editing; Sathammai Priya Narayanan- formal analysis and Deog-Hwan Oh- Conceptualization, Methodology, Supervision, Project administration, writing- review\&editing.

\section{Declarations of interests}

None

\section{References}

1. Albertsson AC, Andersson SO, Karlsson S (1987) The mechanism of biodegradation of polyethylene. Polym Degrad Stab 18(1):73-87

2. Auta HS, Emenike CU, Jayanthi B, Fauziah SH (2018) Growth kinetics and biodeterioration of polypropylene microplastics by Bacillus species and Rhodococcus species isolated from mangrove sediment. Mar Pollut Bull 127:15-21

3. Badahit G, Kumar J, Singh A (2018) Screening of Plastic Degrading Pseudomonas spp. from soil. Int J Sci Eng Res 9:484-489

4. Benson NU, Fred-Ahmadu OH, Bassey DE, Atayero AA (2021) COVID-19 pandemic and emerging plastic-based personal protective equipment waste pollution and management in Africa. Journal of Environmental Chemical Engineering 9(3):105222

5. Bødtker G, Thorstenson T, Lillebø BLP, Thorbjørnsen BE, Ulvøen RH, Sunde E, Torsvik T (2008) The effect of long-term nitrate treatment on SRB activity, corrosion rate and bacterial community composition in offshore water injection systems. J Ind Microbiol Biotechnol 35(12):1625-1636

6. Cassone BJ, Grove HC, Elebute O, Villanueva SM, LeMoine CM (2020) Role of the intestinal microbiome in low-density polyethylene degradation by caterpillar larvae of the greater wax moth, Galleria mellonella. Proceedings of the Royal Society B 287(1922): 20200112 
7. Costerton JW, Stewart PS, Greenberg EP (1999) Bacterial biofilms: a common cause of persistent infections. Science284(5418):pp 1318-1322

8. COVID C (2020) Global Cases by the Center for Systems Science and Engineering (CSSE) at Johns. Hopkins University.Johns Hopkins CSSE

9. Das MP, Kumar S (2015) An approach to low-density polyethylene biodegradation by Bacillus amyloliquefaciens. 3 Biotech 5(1):81-86

10. Devi RS, Kannan VR, Natarajan K, Nivas D, Kannan K, Chandru S, Antony AR (2016) The role of microbes in plastic degradation. Environ, Waste Manage341

11. Dharmaraj S, Ashokkumar V, Hariharan S, Manibharathi A, Show PL, Chong CT, Ngamcharussrivichai C (2021) The COVID-19 pandemic face mask waste: a blooming threat to the marine environment. Chemosphere272:129601

12. Dhawan R, Bisht BMS, Kumar R, Kumari S, Dhawan SK (2019) Recycling of plastic waste into tiles with reduced flammability and improved tensile strength. Process Safety Environmental Protection124:299-307

13. Fan Y, Qiao J, Lu Z, Fen Z, Tao Y, Lv F, Bie X (2020) Influence of different factors on biofilm formation of Listeria monocytogenes and the regulation of cheY gene. Food Res Int 137:109405

14. Gajendiran A, Krishnamoorthy S, Abraham J (2016) Microbial degradation of low-density polyethylene (LDPE) by Aspergillusclavatus strain JASK1 isolated from landfill soil. 3 Biotech 6(1):52. DOI 10.1007/s13205-016-0394-x

15. Gu JD (2003) Microbiological deterioration and degradation of synthetic polymeric materials: recent research advances. International biodeterioration\& biodegradation 52(2):69-91

16. Gupta KK, Devi D (2020) Characteristics investigation on biofilm formation and biodegradation activities of Pseudomonas aeruginosa strain ISJ14 colonizing low density polyethylene(LDPE)surface. Heliyon 6(7):e04398

17. Harshvardhan K, Jha B (2013) Biodegradation of low-density polyethylene by marine bacteria from pelagic waters, Arabian Sea, India. Mar Pollut Bull 77(1-2):100-106

18. Howard GT, Hilliard NP (1999) Use of Coomassie blue-polyurethane interaction inscreening of polyurethanase proteins andpolyurethanolytic bacteria. International biodeterioration \& biodegradation 43(1-2):23-30

19. http://www.ripublication.com/ ijbbr.html

20. https://theconversation.com/polypropylene-the-material-now-recommended-for-covid-19-maskfilters-what-it-is-where-to-get-it-149613

21. Kapri A, Zaidi MGH, Satlewal A, Goel R (2010) SPION-accelerated biodegradation of low-density polyethylene by indigenous microbial consortium. International Biodeterioration\& Biodegradation 64(3):238-244

22. Kumari N, Vashishtha A, Saini P, Menghani $E$ (2013) Isolation, identification and characterization of oil degrading bacteria isolated from the contaminated sites of Barmer, Rajasthan. Int $\mathrm{J}$ 
BiotechnolBioeng Res4(5): 429-436

23. Kyaw BM, Champakalakshmi R, Sakharkar MK, Lim CS, Sakharkar KR (2012) Biodegradation of low density polythene (LDPE) by Pseudomonas species. Indian journal of microbiology 52(3):411-419

24. Lee HM, Kim HR, Jeon E, Yu HC, Lee S, Li J, Kim DH (2020) Evaluation of the Biodegradation Efficiency of Four Various Types of Plastics by Pseudomonas aeruginosa isolated from the Gut Extract of superworms. Microorganisms8(9):1341

25. Montazer Z, HabibiNajafi MB, Levin DB (2019) Microbial degradation of low-density polyethylene and synthesis of polyhydroxyalkanoate polymers. Can J Microbiol 65(3):224-234

26. Munir E, Harefa RSM, Priyani N, Suryanto D (2018) Plastic degrading fungi Trichodermaviride and Aspergillusnomius isolated from local landfill soil in Medan. In IOP Conference Series: Earth and Environmental Science 126(1):012145

27. Nakajima -Kambe T, Onuma F, Akutsu Y, Nakahara T (1997) Determination of the polyester polyurethane breakdown products and distribution of the polyurethane degrading enzyme of Comamonasacidovorans strain TB-35. J Ferment Bioeng 83(5):456-460

28. Nzediegwu C, Chang SX (2020) Improper solid waste management increases potential for COVID-19 spread in developing countries. Resources conservation recycling 161:104947

29. Peixoto J, Silva LP, Krüger RH (2017) Brazilian Cerrado soil reveals an untapped microbial potential for unpretreated polyethylene biodegradation. Journal of hazardous materials324:634-644

30. Pramila R, Ramesh KV (2015) Potential biodegradation of low density polyethylene (LDPE) by Acinetobacterbaumannii. African Journal of Bacteriology Research 7(3):24-28

31. Prata JC, Silva AL, Walker TR, Duarte AC, Rocha-Santos T (2020) COVID-19 pandemic repercussions on the use and management of plastics. Environmental Science Technology 54(13):7760-7765

32. Roberts C, Edwards S, Vague M, León-Zaya R, Scheffer H, Chan G, Mellies JL (2020) Environmental Consortium Containing Pseudomonas and Bacillus Species Synergistically Degrades Polyethylene Terephthalate Plastic. Msphere 5(6):e01151-e01120

33. Saberian M, Li J, Kilmartin-Lynch S, Boroujeni M (2021) Repurposing of COVID-19 single-use face mask for pavements base/subbase. Sci Total Environ 769:145527

34. Sah A, Kapri A, Zaidi MGH, Negi H, Goel R (2010)Implications of fullerene-60 upon in-vitro LDPE biodegradation. Journal of microbiology and biotechnology 20(5): 908-916

35. Sangkham S (2020) Face mask and medical waste disposal during the novel COVID-19 pandemic in Asia. Case Studies in Chemical Environmental Engineering 2:100052

36. Shah AA, Nawaz A, Kanwal L, Hasan F, Khan S, Badshah M (2015) Degradation of poly ( $\varepsilon$ caprolactone) by a thermophilic bacterium Ralstoniasp. strain MRL-TL isolated from hot spring. International Biodeterioration\& Biodegradation 98:35-42

37. Skariyachan S, Megha M, Kini MN, Mukund KM, Rizvi A, Vasist K (2015) Selection and screening of microbial consortia for efficient and ecofriendly degradation of plastic garbage collected from urban and rural areas of Bangalore, India. Environmental monitoring and assessment187(1): 1-14 
38. Sohrabi C, Alsafi Z, O'Neill N, Khan M, Kerwan A, Al-Jabir A, Agha R (2020) World Health Organization declares global emergency: A review of the 2019 novel coronavirus (COVID-19). International journal of surgery $76: 71-76$

39. Szita G, Tabajdi V, Fábián A, Biró G, Reichart O, Körmöczy PS (1998) A novel, selective synthetic acetamide containing culture medium for isolating Pseudomonas aeruginosa from milk. Int J Food Microbiol 43(1-2):123-127

40. Vague M, Chan G, Roberts C, Swartz NA, Mellies JL (2019) Pseudomonas isolates degrade and form biofilms on polyethylene terephthalate (PET) plastic. BioRxiv647321.

41. World Health Organization (2020) Coronavirus disease 2019 (COVID-19): situation report 82

42. Yang J, Yang Y, Wu WM, Zhao J, Jiang L (2014) Evidence of polyethylene biodegradation by bacterial strains from the guts of plastic-eating waxworms. Environ Sci Technol 48(23):13776-13784

43. Zahra S, Abbas SS, Mahsa MT, Mohsen N (2010) Biodegradation of low-density polyethylene (LDPE) by isolated fungi in solid waste medium. Waste management 30(3):396-401

44. Zerbi G, Gallino G, Del Fanti N, Baini L (1989) Structural depth profiling in polyethylene films by multiple internal reflection infra-red spectroscopy. Polymer 30(12):2324-2327

\section{Figures}



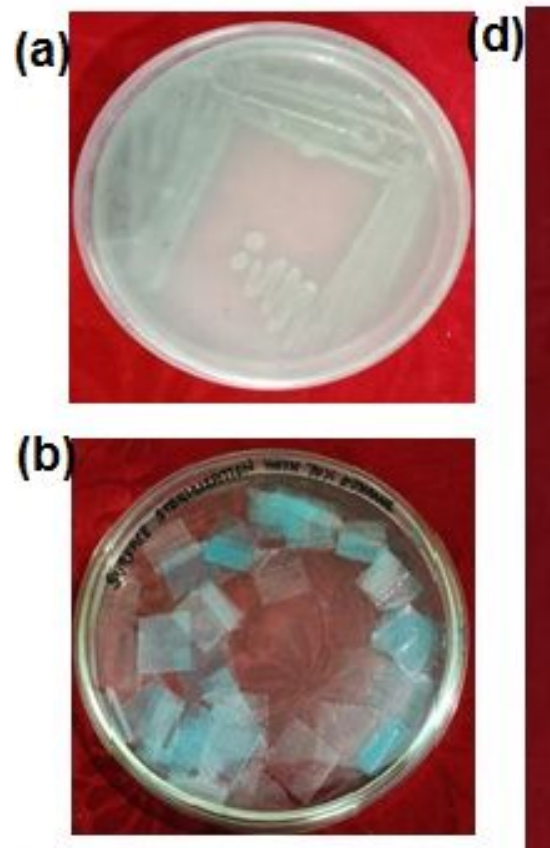

(c)
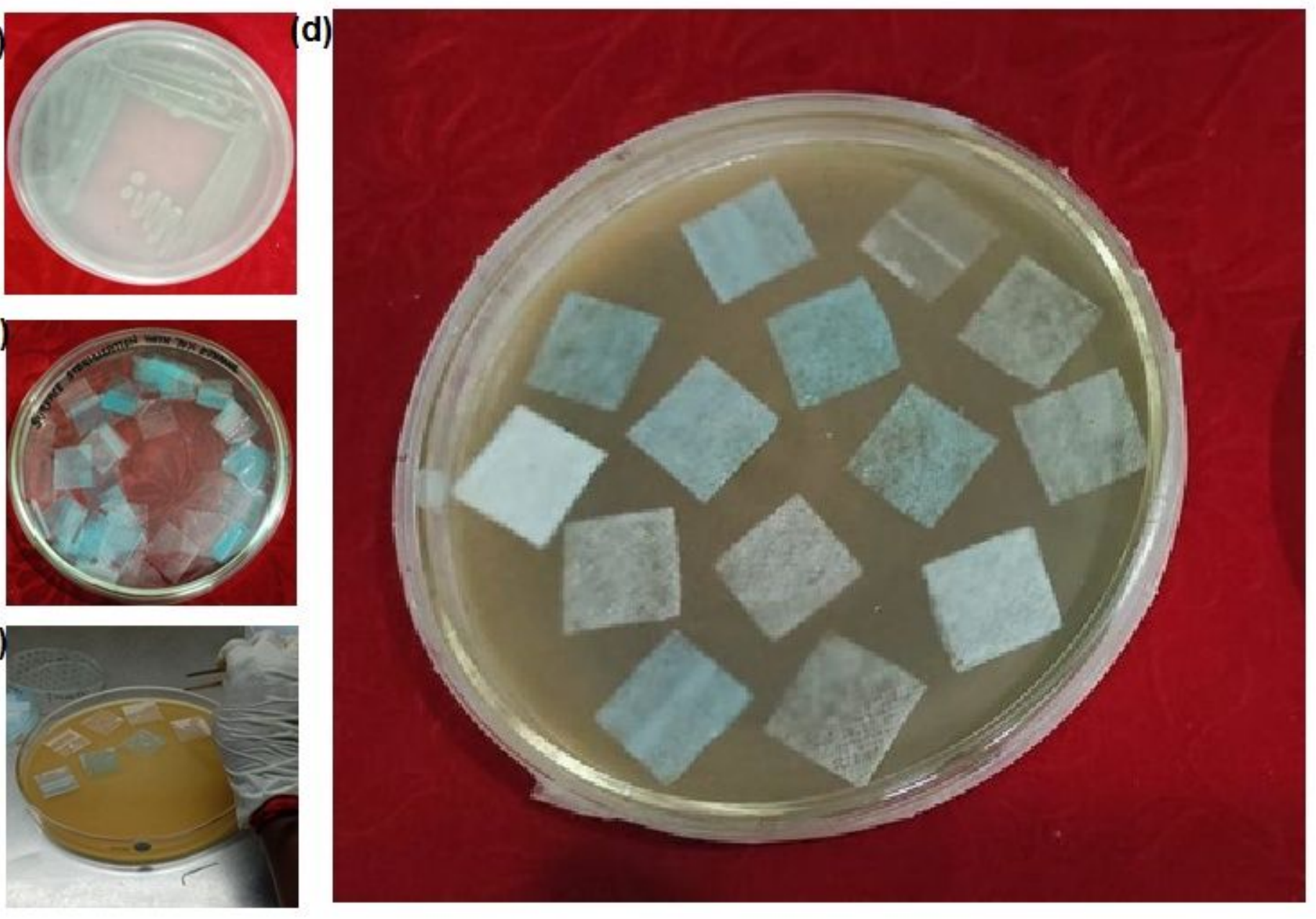

\section{Figure 1}

A-Pure culture of Psedomonasaeruginosastrain; B- Pre-treated PP mask pieces; C- PP mask placed on to the Culture inoculated Nutrient Agar plate; D- PP mask pieces on Nutrient agar after 30 days. 


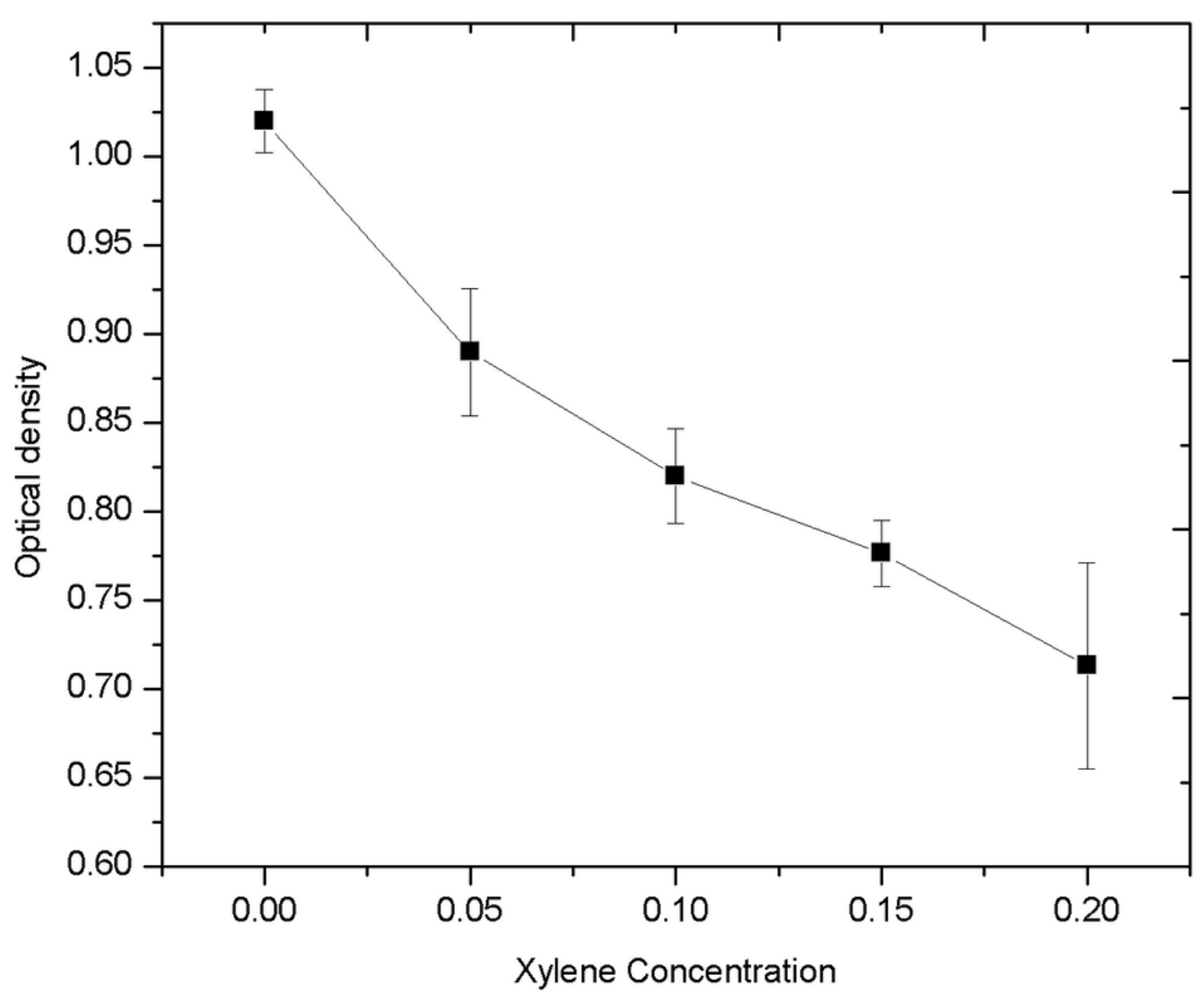

Figure 2

Cell surface Hydrophobicity of P.aeruginosa 


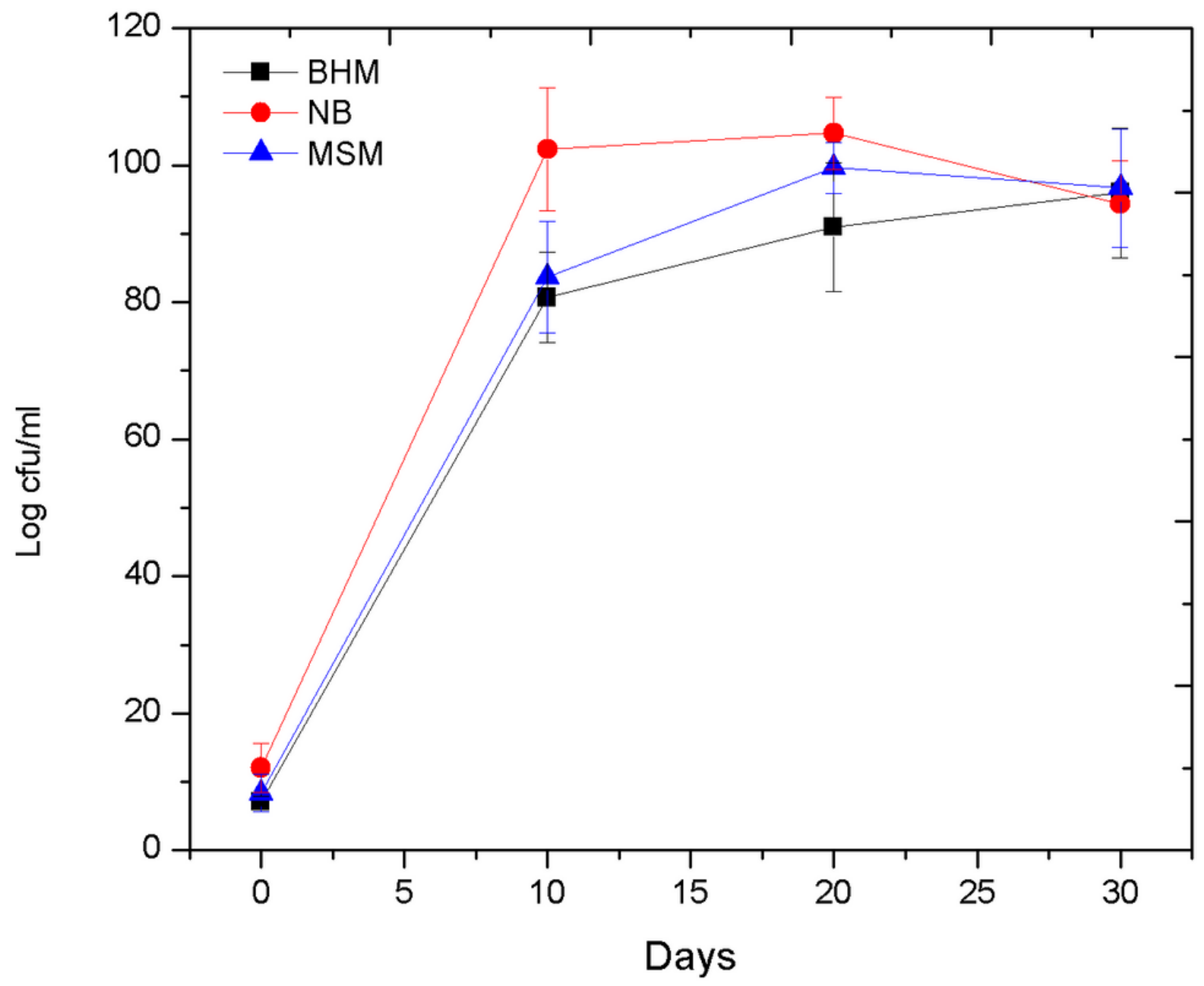

Figure 3

Viability of surface attached P.aeruginosa 


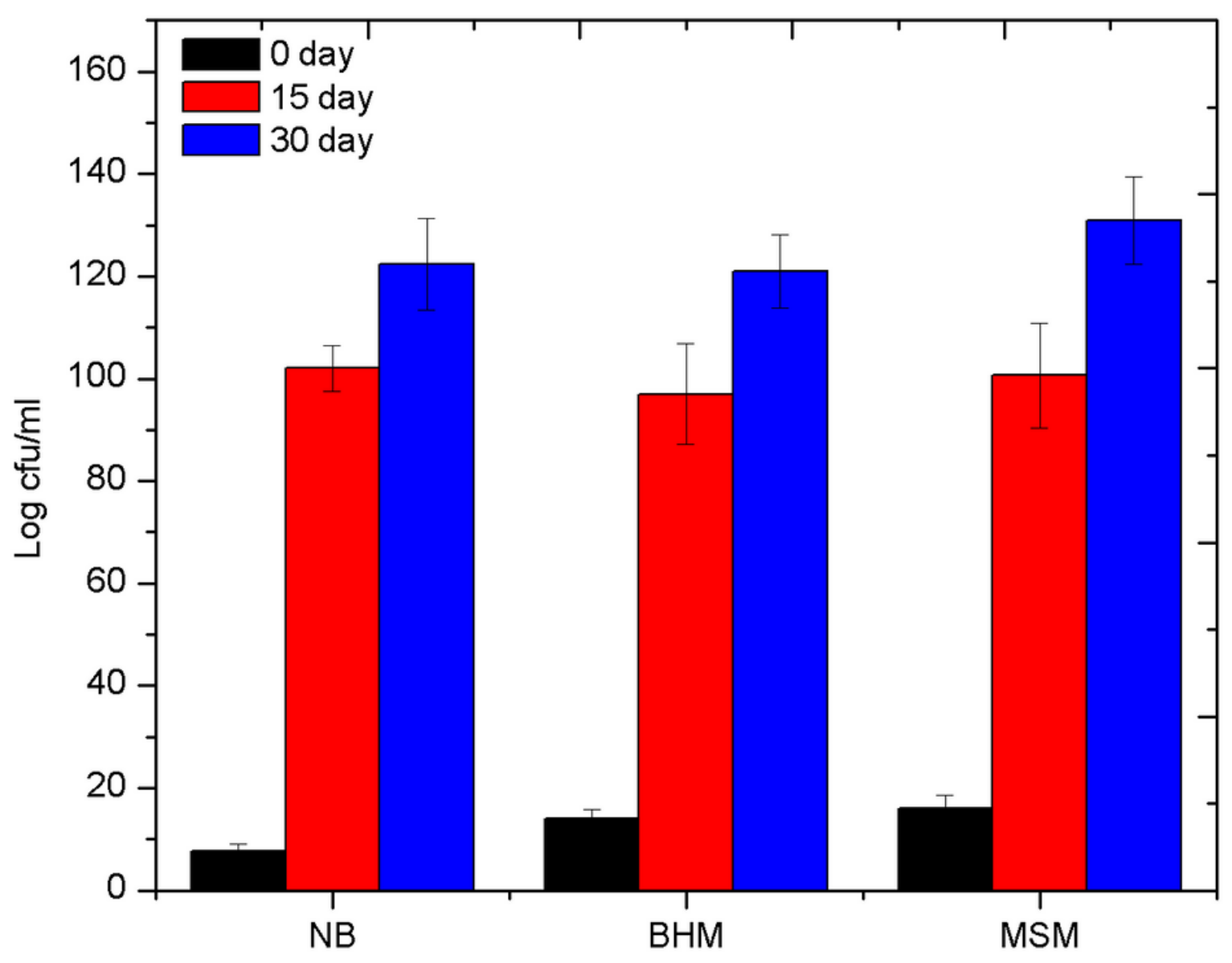

Figure 4

Planktonic growth of P.aeruginosa in different culture media used 


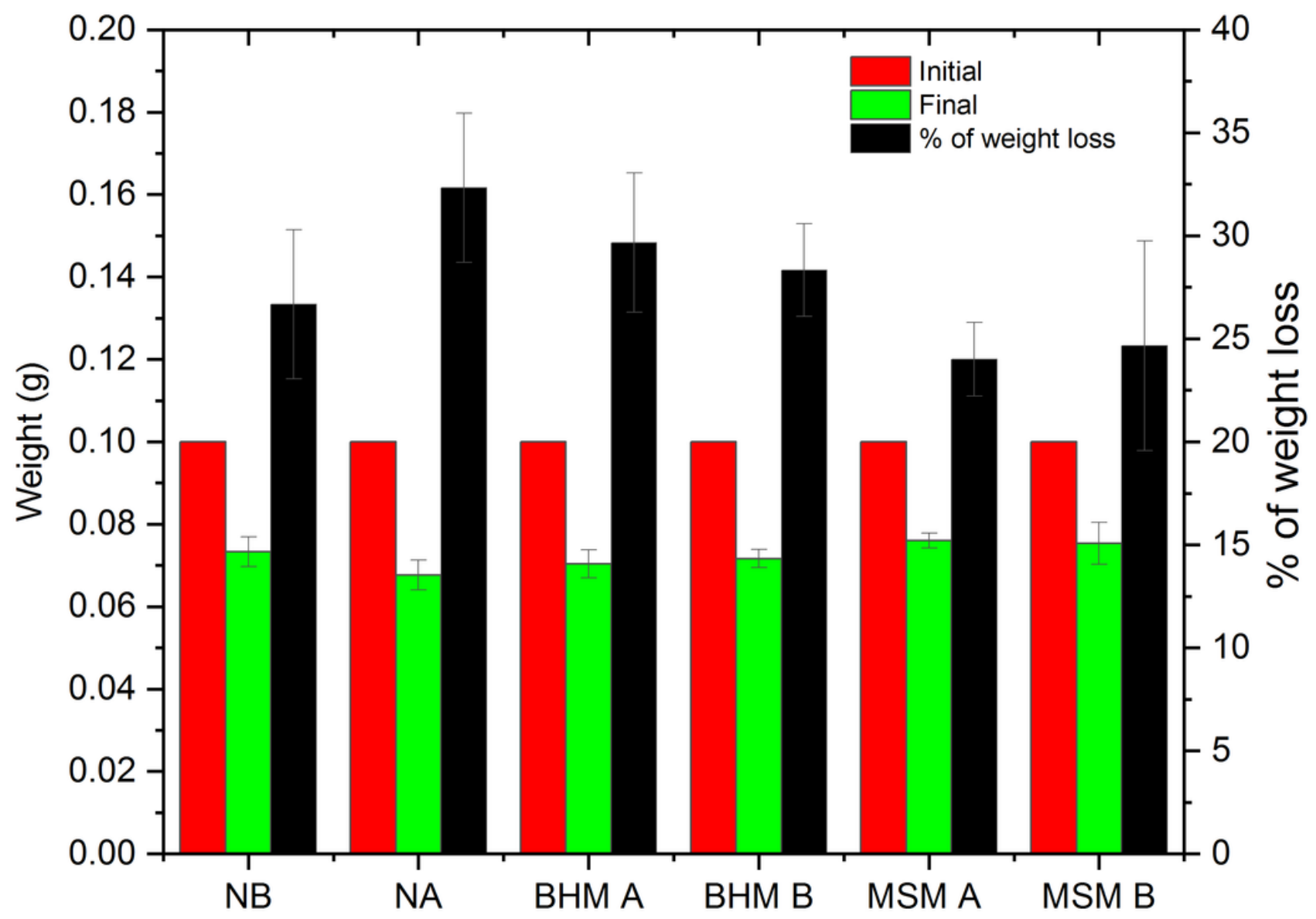

Figure 5

Dry weight of PP films after 30 days of incubation (control and treated) 


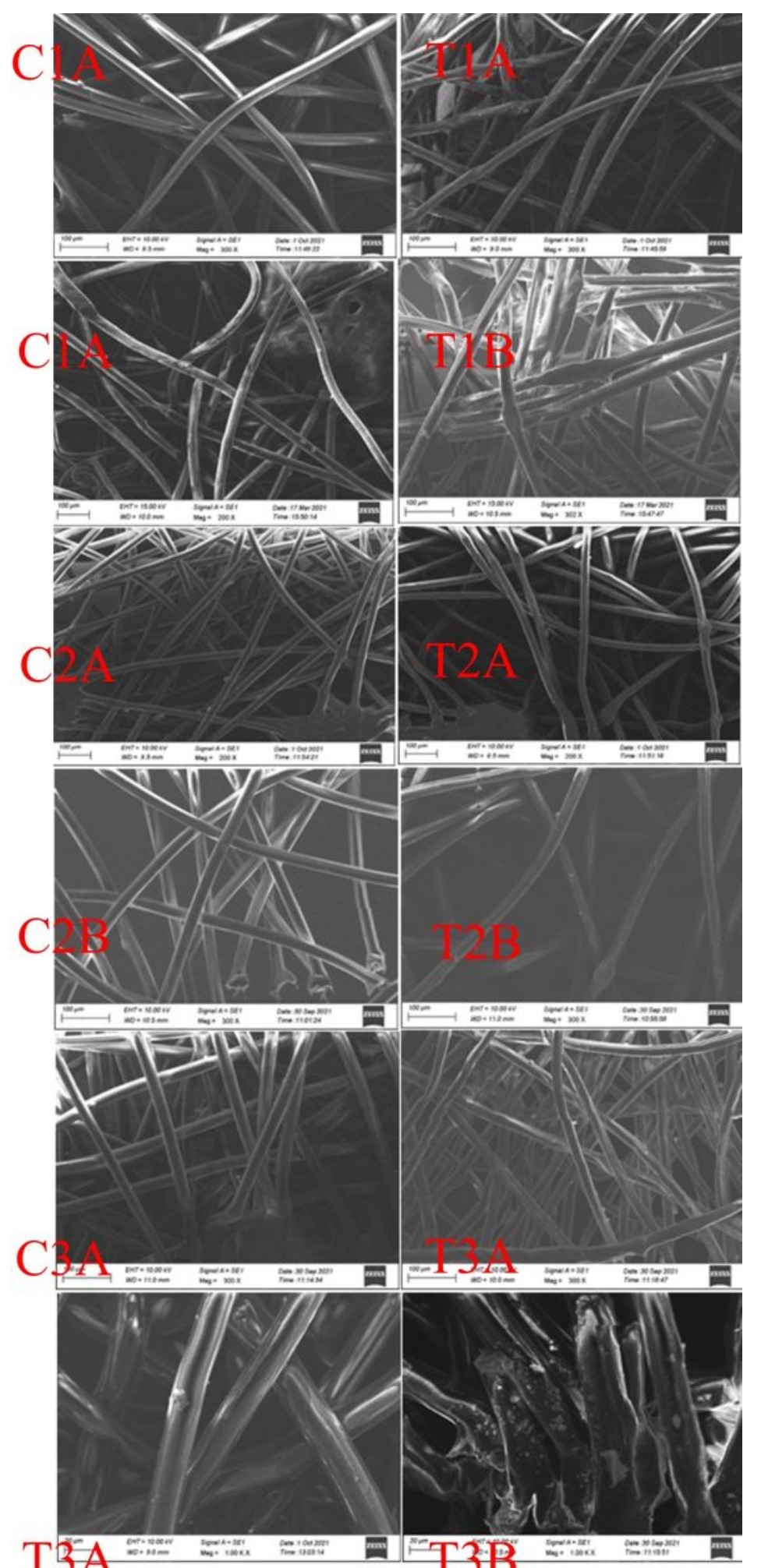

\section{Figure 6}

SEM images of PP films placed in Nutrient medium, BHM, and MSM; C1A, C1B- control; T1A and T1Btreated with P. aeruginosain NA and NB media respectively. C2A, C2B- control; T2A and T2B-treated with P. aeruginosa in BHM agar and broth respectively. C3A, C3B-control; T3A and T3B-treated with P.aeruginosain MSM agar and broth respectively 


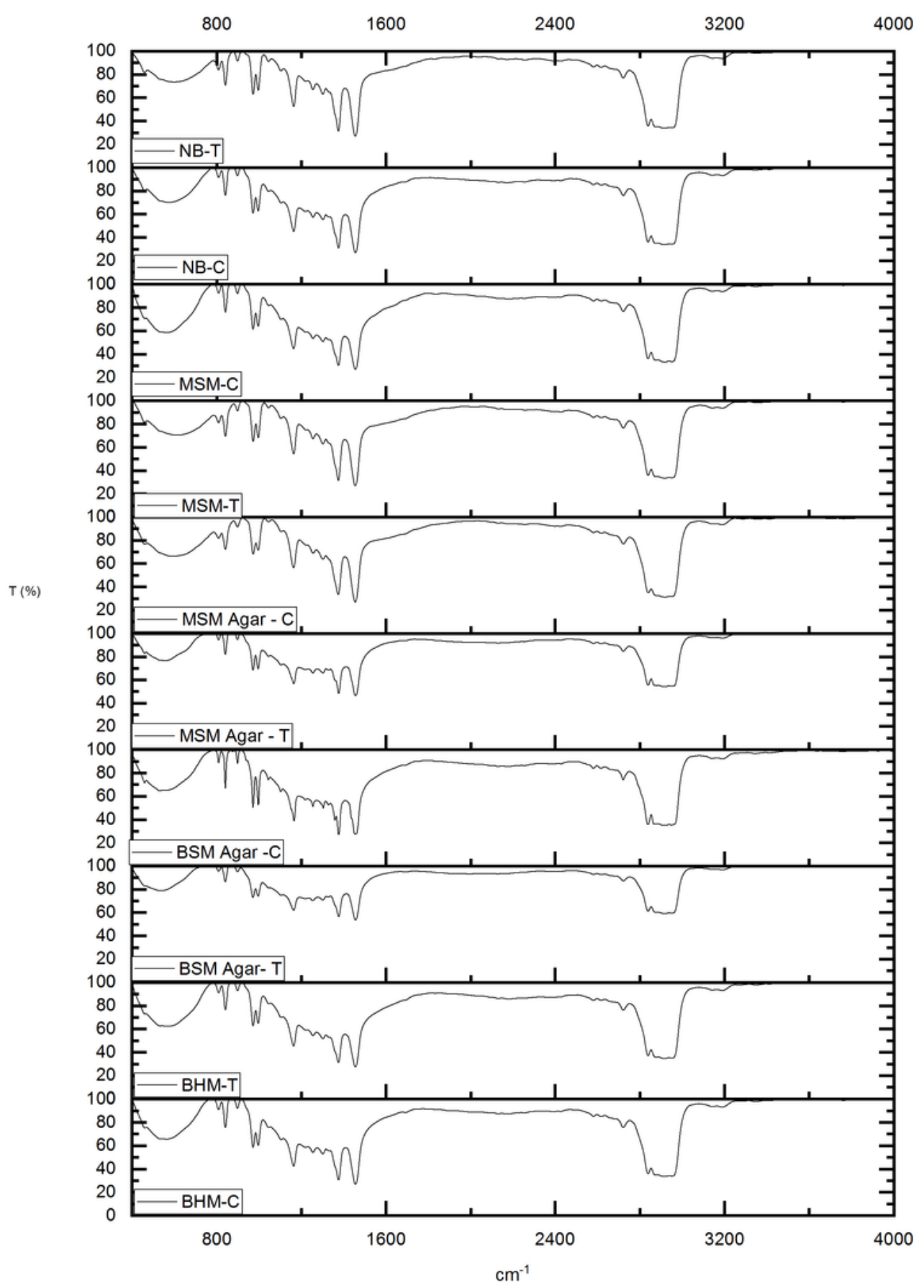

Figure 7

FTIR spectra of PP films 